Check for updates

Cite this: RSC Adv., 2019, 9, 13533

Received 20th December 2018 Accepted 22nd April 2019

DOI: 10.1039/c8ra10440a

rsc.li/rsc-advances

\section{Preparation of functionalized magnetic nanoparticles conjugated with feroxamine and their evaluation for pathogen detection $\uparrow$}

\author{
Diana Martínez-Matamoros, (DD a Socorro Castro-García, (DD a Miguel Balado, (DD b \\ Adriana Matamoros-Veloza, (iD c Miller Alonso Camargo-Valero, (iD df

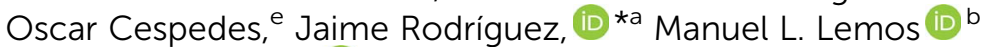 \\ and Carlos Jiménez (iD *a
}

\begin{abstract}
This work reports the preparation of a conjugate between amino-functionalized silica magnetite and the siderophore feroxamine. The morphology and properties of the conjugate and intermediate magnetic nanoparticles (MNPs) were examined by powder X-ray diffraction (XRD), Fourier Transform Infrared spectroscopy (FT-IR), Raman spectroscopy, X-ray photoelectron spectroscopy (XPS), magnetization studies, zeta potential measurements, Transmission Electron Microscopy (TEM) and Energy Dispersive Xray (EDX) mapping. Furthermore, this study investigated the interaction between the functionalized magnetic NPs and Yersinia enterocolitica wild type (WC-A) using Scanning Electron Microscopy (SEM) and TEM images. In addition, the interaction between MNPs and a $Y$. enterocolitica mutant strain lacking feroxamine receptor FoxA, was also used to study the binding specificity. The results showed that the capture and isolation of $Y$. enterocolitica by the MNPs took place in all cases. Moreover, the specific interaction between the MNP conjugate and bacteria did not increase after blocking the free amine groups with $t$-butoxycarbonyl (Boc) and carboxylic acid $(\mathrm{COOH})$ functional groups. Electrostatic surface interactions instead of molecular recognition between MNP conjugate and feroxamine receptor seem to rule the attachment of bacteria to the conjugate.
\end{abstract}

\section{Introduction}

A growing interest in magnetic nanoparticles (MNP) based on magnetite $\left(\mathrm{Fe}_{3} \mathrm{O}_{4}\right)$ has been observed over the last 10 years in analytical sensing and nanomedicine due to its strong magnetic properties and biocompatibility. ${ }^{1}$ The magnetic field of MNP plays a key role in the capture and bio-separation of analytes.

${ }^{a}$ Centro de Investigacións Cientificas Avanzadas (CICA), Departamento de Química, Facultade de Ciencias, Universidade da Coruña, 15071 A Coruña, Spain. E-mail: jaime.rodriguez@udc.es; carlos.jimenez@udc.es

${ }^{b}$ Department of Microbiology and Parasitology, Institute of Aquaculture, Universidade de Santiago de Compostela, Campus Sur, Santiago de Compostela 15782, Spain

'Institute of Functional Surfaces, School of Mechanical Engineering, University of Leeds, Leeds LS2 2JT, UK

${ }^{d}$ BioResource Systems Research Group, School of Civil Engineering, University of Leeds, Leeds LS2 9JT, UK

${ }^{e}$ Faculty of Mathematics and Physical Sciences, School of Physics and Astronomy, University of Leeds, Leeds LS2 9JT, UK

${ }^{f}$ Departamento de Ingeniería Química, Universidad Nacional de Colombia, Campus La Nubia, Manizales, Colombia

$\dagger$ Electronic supplementary information (ESI) available: p-XRD, FT-IR spectra, magnetization hysteresis loops, thermogravimetric analysis (TGA) of blocked NPs, SEM images, TEM images and EDX maps and $Y$. enterocolitica WC-A-MNP interaction assay results for iron and iron deficiency growth conditions. See DOI: $10.1039 / \mathrm{c} 8 \mathrm{ra} 10440 \mathrm{a}$
The functionalization of MNP's surface allows the development of multiple applications such as magnetic hyperthermia, magnetic resonance imaging (MRI), target drug delivery and detection of bacteria, since MNP are capable of capturing bacteria using specific recognition. In fact, MNP are capable of interacting with biological entities such as proteins and bacterial membranes, among others, can be manipulated by an external magnetic field, and are easy to synthesize. ${ }^{2}$

The development of rapid, sensitive and reliable methods for the detection and identification of infectious microorganisms is one of the main concerns in food and health industries. Nowadays, this interest has become more important with the emerge of virulent strains of common pathogenic bacteria and the need of limiting the spread of related contagious diseases. The traditional methods based on cell culturing are usually very slow and time-consuming processes. Numerous rapid and sensitive methods for microbial detection have been developed (e.g., immunoassays, enzyme-linked immunosorbent assays (ELISA) and polymerase chain reaction methodologies (PCR)). ${ }^{3}$ However, they are not effective in complex systems when bacteria are present in low concentrations. An emerging research area based on the magnetic, electronic, photonic, and optical properties and functionalization of MNP has being adopted to develop alternative methods based on the isolation 
of pathogenic bacteria using nanomaterials for biological identification. $^{4}$

The specificity of MNP is based on the chemical recognition of pathogenic bacteria through the conjugation of MNP with antibodies, aptamers, bioproteins, carbohydrates and bacteriophages. ${ }^{1}$ Moreover, MNP can be also coupled to siderophores that are recognized by specific membrane receptors of microorganisms. ${ }^{5}$ Siderophores are small organic molecules recognised for playing a role in the mechanisms controlling $\mathrm{Fe}^{3+}$ uptake by bacteria. ${ }^{6,7}$ So far, three different approaches have been documented for the detection of microbial pathogens using siderophore scaffolds. The first one utilizes an immobilized siderophore to capture human pathogens, in which a siderophore conjugate is attached to gold-plated glass chips through bovine serum albumin (BSA). ${ }^{\mathbf{8}, \mathbf{9}}$ Other example is a modified, artificial siderophore complex attached to the surface of an Au electrode and placed on quartz crystal microbalance (QCM) chips. ${ }^{10,11}$ A recent work using this approach, documented the use of a siderophore-based active bacterial removal integrated in a localized surface plasmon resonance (LSPR) sensing platform. ${ }^{12}$ The second approach employs a siderophore attached to functionalized quantum dots (QDs) for the bacterial interaction with a specific receptor. ${ }^{13}$ The third approach uses functionalized agarose columns bound to a specific bacterial siderophore for the capture of siderophorebinding proteins. ${ }^{14}$ However, the conjugation of siderophores and magnetic nanoparticles to isolate and capture pathogenic bacteria has not been studied yet.

Herein, we report the first synthesis of a conjugate between amino-functionalized silica magnetite and the siderophore feroxamine, the blocking of free amine groups on the surface of amino-functionalized silica magnetite and the conjugate with $t$ butoxycarbonyl (Boc) and carboxylic acid $(-\mathrm{COOH})$ functional groups and its evaluation for the capture of wild type (WC-A) and a mutant lacking feroxamine receptor FoxA (FoxA WC-A 12-8) Y. enterocolitica strains.

\section{Experimental}

All starting materials, reagents and solvents were obtained from commercial suppliers and used without further purification. Argon gas was used to avoid the presence of moisture and oxygen in sensitive reactions. Size exclusion chromatography was performed on Sephadex ${ }^{\mathrm{TM}}$ LH-20 resins. LREIMS and HRESIMS were measured on Applied Biosystems QSTAR Elite.

\section{Synthesis}

Synthesis of $\mathrm{Fe}_{3} \mathrm{O}_{4}$ magnetic nanoparticles (MNP). ${ }^{15}$ A solution of $0.5 \mathrm{~g}$ of iron(III) acetylacetonate $\left(\mathrm{Fe}(\mathrm{acac})_{3}\right)$ in $10 \mathrm{~mL}$ of benzyl alcohol was sonicated for $2 \mathrm{~min}$, transferred to a heating block and left to react at $180{ }^{\circ} \mathrm{C}$ for $72 \mathrm{~h}$. After that time, the resulting mixture was allowed to cool down before the precipitates were decanted by centrifugation (5000 rpm for $30 \mathrm{~min}$ ), while the supernatant was discarded. The solids were rinsed three times with $96 \%$ ethanol, sonicated and recovered using a magnet.
Synthesis of $\mathrm{SiO}_{2}$ coating of MNP (MNP@SiO $\left.{ }_{2}\right) \cdot{ }^{16} 80 \mathrm{~mL}$ of isopropanol, $4 \mathrm{~mL}$ of ammonia (21\%), $7.5 \mathrm{~mL}$ of distilled water and $0.56 \mathrm{~mL}$ of tetraethyl orthosilicate (TEOS) were carefully added in this order to $2 \mathrm{~g}$ of MNP. The mixture was heated at $40{ }^{\circ} \mathrm{C}$ for $2 \mathrm{~h}$ with continuous stirring and then sonicated for $1 \mathrm{~h}$. After that time, the MNP were removed from the solution using a magnet and re-dispersed in $30 \mathrm{~mL}$ of isopropanol. This coating procedure was repeated a second time. Finally, the $\mathrm{SiO}_{2}$ coated MNP were rinsed with ethanol and separated from the dispersion using a magnet.

Synthesis of amino-functionalized silica magnetite ( $\left.\mathbf{M N P @ S i O}{ }_{2} @ \mathbf{N H}_{2}\right) \cdot{ }^{17} \mathrm{~A}$ modified procedure described by Chen et $a .^{17}$ was used for the functionalization of $\mathrm{MNP@SiO}_{2}$. For that, $500 \mathrm{mg}$ of $\mathrm{MNP}_{\mathrm{S}} \mathrm{SiO}_{2}$ were rinsed and sonicated three times with $3 \mathrm{~mL}$ of dimethylformamide (DMF). Then, the particles were re-suspended in $9 \mathrm{~mL}$ of DMF and $9 \mathrm{~mL}$ of 3aminopropyltriethoxysilane (APTES). The resulting mixture was then shaken at $60{ }^{\circ} \mathrm{C}$ for $12 \mathrm{~h}$. Finally, the functionalized particles (MNP@SiO $\mathrm{MNH}_{2}$ ) were separated with a magnet and sonicated with $96 \%$ ethanol, three times.

Synthesis of feroxamine (2). ${ }^{18} 100 \mathrm{mg}(0.15 \mathrm{mmol})$ of deferoxamine mesylate (1) salt and $53.0 \mathrm{mg}(0.15 \mathrm{mmol})$ of $\mathrm{Fe}(\mathrm{acac})_{3}$ were dissolved in $5 \mathrm{~mL}$ of distilled water and left stirring overnight. The resulting product was washed three times with $20 \mathrm{~mL}$ of EtOAc and then, the solvent was removed under vacuum using a rotavapor. The aqueous phase was freeze-dried to obtain feroxamine as a red solid ( $94.4 \mathrm{mg}, 78 \%$ yield). (+)-HR-ESIMS $\mathrm{m} /$ $z 614.2751[\mathrm{M}+\mathrm{H}]^{+}$(calculated for $\mathrm{C}_{25} \mathrm{H}_{45} \mathrm{FeN}_{6} \mathrm{O}_{8}$ : 614.2729).

Synthesis of $\boldsymbol{N}$-succinyl feroxamine (3).$^{19} 350 \mathrm{mg}$ (3.50 mmol) of succinic anhydride were added to a solution of $100 \mathrm{mg}(0.17$ $\mathrm{mmol}$ ) of feroxamine in $5 \mathrm{~mL}$ of pyridine. The resulting mixture was stirred at room temperature for $16 \mathrm{~h}$. After that time, the excess of pyridine was eliminated in a rotavapor under vacuum. The red solid product was purified by size exclusion chromatography using methanol as eluent to separate $93.1 \mathrm{mg}$ of $\mathrm{N}$ succinyl feroxamine (3) as a dark red solid. (+)-HR-ESIMS $\mathrm{m} / \mathrm{z}$ $736.2700[\mathrm{M}+\mathrm{Na}]^{+}$; (calculated for $\mathrm{C}_{29} \mathrm{H}_{49} \mathrm{FeN}_{6} \mathrm{O}_{11} \mathrm{Na}$ : 736.2706).

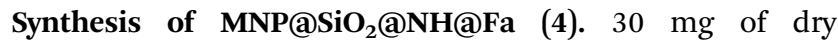
$\mathrm{MNP}_{2} @ \mathrm{SiO}_{2} @ \mathrm{NH}_{2}$ were rinsed twice with DMF and sonicated for 30 minutes. A solution of $N$-succinyl feroxamine $(3 ; 200 \mathrm{mg}$, $0.30 \mathrm{mmol}$ ), benzotriazole-1-yl-oxy-tris-(dimethylamino)phosphonium hexafluorophosphate (BOP, $173 \mathrm{mg}, \quad 0.45$ $\mathrm{mmol}$ ), 1-hydroxybenzotriazole (HOBt, $46 \mathrm{mg}, 0.39 \mathrm{mmol}$ ) and $N, N$-diisopropylethylamine (DIPEA, $128.8 \mathrm{mg}, 1.21 \mathrm{mmol}$ ) in $10 \mathrm{~mL}$ of DMF was added dropwise to a suspension of $30 \mathrm{mg}$ of $\mathrm{MNP} @ \mathrm{SiO}_{2} @ \mathrm{NH}_{2}$ in $3 \mathrm{~mL}$ of DMF under sonication in dry and oxygen free conditions using an argon gas atmosphere. ${ }^{20}$ The mixture was left stirring at room temperature overnight. Finally, the resulting conjugate (MNP@SiO $@$ @NH@Fa, 4) was separated from the suspension with a magnet and the separated solid was rinsed and sonicated 5 times with $10 \mathrm{~mL}$ of ethanol. The solid was vacuum dried for $24 \mathrm{~h}$.

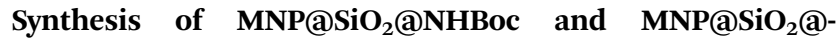

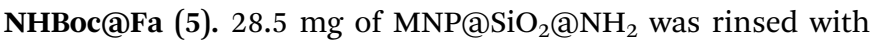
dry DMF and sonicated twice for 5 minutes under an argon gas 
atmosphere and then suspended in $10 \mathrm{~mL}$ of dry DMF. After that, $200 \mathrm{mg}$ of $\mathrm{Boc}_{2} \mathrm{O}$ (di-tert-butyl dicarbonate) were dissolved in dry DMF and mixed with the nanoparticles. The reaction mixture was sonicated for $30 \mathrm{~min}$ and then stirred at room temperature in an orbital shaker at $200 \mathrm{rpm}$ for $24 \mathrm{~h}$. Finally, the solids were separated using a magnet and rinsed with $10 \mathrm{~mL}$ of ethanol and sonicated five times. The solids were then vacuum

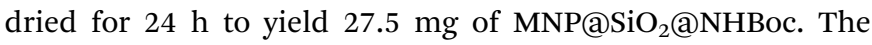
same procedure was repeated for $13.6 \mathrm{mg}$ of $\mathrm{MNP} @ \mathrm{SiO}_{2} @$

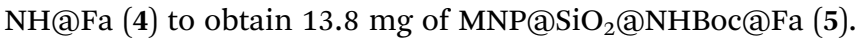

Synthesis of $\mathrm{MNP}_{3} \mathrm{SiO}_{2} @ \mathrm{NHCOOH}$ and $\mathrm{MNP}_{2} \mathrm{SiO}$ NHCOOH@Fa (6).25 mg of MNP@SiO $\mathrm{MNH}_{2}$ were first rinsed with dry pyridine and sonicated twice for 5 minutes under an argon atmosphere and then suspended in $10 \mathrm{~mL}$ of dry pyridine. After this, $200 \mathrm{mg}$ of succinic anhydride were added to the nanoparticles. The reaction mixture was sonicated $30 \mathrm{~min}$ and then stirred at room temperature in an orbital shaker at $200 \mathrm{rpm}$ for $24 \mathrm{~h}$. Finally, the solids were separated using a magnet, rinsed and sonicated five times using $10 \mathrm{~mL}$ of ethanol and vacuum

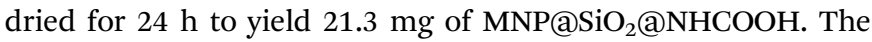
same procedure was repeated for $9.3 \mathrm{mg}$ of ${\mathrm{MNP} @ \mathrm{SiO}_{2} @ \mathrm{NH} @ \mathrm{Fa}}$

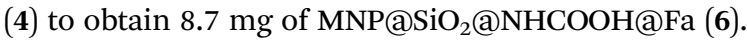

\section{Characterization}

Powder X-ray diffraction (XRD). XRD analyses of samples containing MNP were performed using a Bruker D8 diffractometer $\left(\mathrm{CuK}_{\alpha}\right)$ with a scan range between 2 and $702 \theta$ at 0.05 $2 \theta \mathrm{min}^{-1}$. The MNP containing samples were re-dispersed in ethanol and mounted onto a poly(methyl methacrylate) specimen holder for analysis. Peak identification was performed by using X'Pert High Score Plus software by comparing the collected diffraction data with the International Centre for Diffraction Data database.

FT-IR and Raman spectroscopy. FT-IR analyses were carried out on powdered nanoparticle samples using an A2-Technology MicroLab Portable mid-IR spectrometer equipped with a diamond internal reflection (DATR). For the analysis, the background was collected without deposition of the sample and then a sample was re-dispersed in ethanol and placed onto the diamond window of the instrument. Individual spectra (4096) were acquired between 650 to $4000 \mathrm{~cm}^{-1}$ at a resolution of $1 \mathrm{~cm}^{-1}$ and then co-added and processed using Origin 8 (OriginLab, Northampton, MA, USA). Raman analyses were carried out in a LabRAM HR 800 Horiba Scientific spectrometer, with a $633 \mathrm{~nm}$ laser using a 10\% power $(\sim 1 \mathrm{~mW})$ and a diffraction grating of $600 \mathrm{ln}$ per $\mathrm{mm}$. Each spectrum included ten measurements of 300 seconds (total measuring time 3000 seconds).

X-ray photoelectron spectroscopy (XPS). Analysis of the samples was performed using a Thermo Scientific K-Alpha ESCA instrument equipped with aluminum $\mathrm{K}_{\alpha}$ monochromatized radiation at $1486.6 \mathrm{eV}$ X-ray source. Due to the no conductor nature of samples, it was necessary to use an electron flood gun to minimize surface charging. Neutralization of the surface charge was performed by using both a low energy flood gun (electrons in the range 0 to $14 \mathrm{eV}$ ) and a low energy Argon ions gun. The XPS measurements were carried out using monochromatic Al- $\mathrm{K}_{\alpha}$ radiation $(h \nu=1486.6 \mathrm{eV})$. Photoelectrons were collected from a take-off angle of $90^{\circ}$ relative to the sample surface. The measurement was done in a Constant Analyser Energy mode (CAE) with a $100 \mathrm{eV}$ pass energy for survey spectra and $20 \mathrm{eV}$ pass energy for high resolution spectra. Charge referencing was done by setting the lower binding energy C1s photo peak at 285.0 eV C1s hydrocarbon peak. Surface elemental composition was determined using the standard Scofield photoemission cross sections. Data analysis and quantification were performed using the Avantage software version 5 from the manufacturer Thermo Scientific.

Magnetic characterization. Magnetization was measured using an Oxford Instruments VSM with a magnetic field of $1 \mathrm{~T}$ and a sensitivity of 10 micro-emu.

Zeta potential analysis. Zeta potential measurements were performed with a NanoBrook 90 Plus from Brookhaven Instruments. Samples were prepared with ultra-pure water and analyzed immediately after sonication.

Thermogravimetric analysis (TGA). Thermogravimetric analyses were carried out using a differential scanning calorimeter STA 449 F3 Jupiter (Netzsch), equipped with a SiC oven. The samples were analyzed in a nitrogen gas atmosphere by an increment of the temperature of $5{ }^{\circ} \mathrm{C} \min ^{-1}$ until $900{ }^{\circ} \mathrm{C}$. Weight loss of each sample was obtained by measurements at different temperatures.

Transmission electron microscopy (TEM) and energy dispersive X-ray (EDX) mapping. Bright field images and maps were acquired at room temperature using a Tecnai TF20 FEGTEM with an operating voltage of $200 \mathrm{keV}$ fitted with a high angle annular dark field (HAADF) detector and a Gatan Orius SC600 CCD camera. EDX maps were collected at room temperature using a FEI Titan G2 S/TEM with an operating voltage of $200 \mathrm{keV}$, a beam current of $0.1 \mathrm{nA}$, a convergence angle of $18 \mathrm{mrad}$ and a HAADF inner angle of $54 \mathrm{mrad}$.

\section{Bacterial capture study with $Y$. enterocolitica strains}

Yersinia enterocolitica WC-A and FoxA WC-A 12-8 were donated by Professor Klaus Hantke (University of Tübingen, Germany). Trypticase Soy Broth (TSB), Trypticase Soy Agar (TSA), Ringers solution and PBS buffer were prepared with distilled water (DW) for biological assays.

Trypticase soy broth (TSB) cultures of $Y$. enterocolitica (wild type and mutant strains) were incubated up to an $\mathrm{OD}_{600}$ between 0.5 and 0.8 in iron deficient conditions by adding $2,2^{\prime}$ bipyridyl up to $100 \mu \mathrm{M}$. Then, $100 \mu \mathrm{L}$ of a $1 \mathrm{mg} \mathrm{mL}^{-1}$ solution of

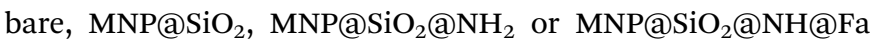
(4) was added to $1 \mathrm{~mL}$ of $1: 100$ dilution of each $Y$. enterocolitica strain (equivalent to ca. $6 \times 10^{6}$ bacterial cells per $\mathrm{mL}$ ) in Phosphate Buffer Saline (PBS) pH 7.4 and incubated for $1 \mathrm{~h}$. The $\mathrm{MNP} /$ bacteria aggregates were separated with a magnet and the supernatant was carefully discarded. The remaining aggregates were rinsed twice with PBS and re-suspended again in fresh PBS. Serial ten-fold dilutions of this suspension were plated on Trypticase Soy Agar (TSA) and incubated at $37^{\circ} \mathrm{C}$ for $24 \mathrm{~h}$. After 
this time, the colony forming units (CFU) captured with the MNP conjugate were counted.

\section{Evaluation of bacteria-nanoparticle interaction}

Scanning electron microscopy (SEM). SEM images were obtained using a FEI Quanta 650 FEGESEM environmental SEM with an Oxford Instruments INCA 350 EDX system/80 mm X-Max SDD detector, EBSD and KE Centaurus EBSD system. Image analysis was performed in ImageJ software. ${ }^{21} Y$. enterocolitica WCA was grown in $10 \mathrm{~mL}$ of TSB until a $\mathrm{OD}_{600}=0.5$, then the bacteria in solution was diluted $1: 10$ and mixed with $1 \mathrm{~mL}$ of

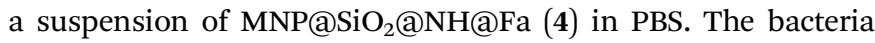
were allowed to interact with the nanoparticles at room temperature for $1 \mathrm{~h}$, then the solids (bacteria-nanoparticles) were separated from the suspension with a magnet, and rinsed twice with $1 \mathrm{~mL}$ of PBS. The captured bacteria were mixed with $2.5 \%$ glutaraldehyde in $0.1 \mathrm{M}$ phosphate buffer and allowed to react for $2 \mathrm{~h}$. After that time, the solids were rinsed twice with $0.1 \mathrm{M}$ phosphate buffer for $30 \mathrm{~min}$. Post-fixed samples were mixed with $1 \%$ osmium tetroxide in $0.1 \mathrm{M}$ phosphate buffer overnight. After that time, the solids were dehydrated using an ascending acetone series (20-40-60-80-100\%) for $30 \mathrm{~min}$, each run. After this, the samples were dried with a Polaron E3000 critical point drying apparatus using liquid carbon dioxide as the transition fluid to afford enough solid to be mounted on $13 \mathrm{~mm}$-diameter pin stubs using double sided adhesive tape. Finally, these samples were coated with platinum to a thickness of $5 \mathrm{~nm}$ using a Cressington 208HR high resolution sputter coating unit.

Transmission electron microscopy (TEM) and EDX maps. Bacteria-nanoparticle interaction was performed as described in the SEM analysis. The solids were fixed in $2.5 \%$ glutaraldehyde and $0.1 \mathrm{M}$ phosphate buffer for $2 \mathrm{~h}$, and rinsed twice (for 30 min each) with a $0.1 \mathrm{M}$ phosphate buffer. 1\% osmium tetroxide in $0.1 \mathrm{M}$ phosphate buffer was added to the post fixed sample and left overnight. After that time, samples were dehydrated using an ascending acetone series (20-40-60-80-100\%), for $30 \mathrm{~min}$ each run. Then, the sample was treated twice with propylene oxide for $20 \mathrm{~min}$ each time. A 50:50 propylene oxide-araldite solution was added to the sample and left overnight, then 25 : 75 and left for several hours, and finally 100\% araldite was added and left for $8 \mathrm{~h}$. The resulting preparation was transferred to embedding moulds with fresh araldite and polymerase overnight at $60{ }^{\circ} \mathrm{C}$. Ultra-thin sections (silver-gold 80-100 nanometers) were picked up on $3.05 \mathrm{~mm}$ grids and stained with saturated uranyl acetate $(120 \mathrm{~min})$.

\section{Results and discussion}

\section{Surface modification and characterization}

The preparation of the conjugate between feroxamine and functionalized silica-coated magnetite nanoparticles through the formation of an amide bond is shown in Fig. 1. First, magnetite $\left(\mathrm{Fe}_{3} \mathrm{O}_{4}, \mathrm{MNP}\right)$ was synthetized using iron(III) acetylacetonate $\left(\mathrm{Fe}(\mathrm{acac})_{3}\right)$ and benzyl alcohol, ${ }^{15,22}$ and then, its surface functionalization was accomplished via a ligand addition mechanism.
The silica-coated magnetite ( $\left.\mathrm{MNP} @ \mathrm{SiO}_{2}\right)$ was then functionalized with 3-aminopropyltriethoxysilane (APTES) using a sol-gel method ${ }^{17}$ that provides abundant $\mathrm{NH}_{2}$ terminal functional groups on the coated particle surface. Silane chemistry was employed for the surface modification of bare $\mathrm{Fe}_{3} \mathrm{O}_{4}$ (MNP). The coating with $\mathrm{SiO}_{2}$ using tetraethoxysilane (TEOS) ${ }^{16}$ provided an adequate scaffold to create tailored variation in the surface functional groups such as amine groups as well as to facilitate the dispersion of the nanoparticles in water, and the posterior functionalization would result to be more uniform. In parallel, commercial deferoxamine mesylate salt (1) was complexed with iron(III) using aqueous $\mathrm{Fe}(\mathrm{acac})_{3}$ to produce ferroxamine complex (2) that was then treated with succinic anhydride to form the corresponding $N$-succinyl feroxamine (3). ${ }^{18}$ The coupling between the amine functionalized silica coated MNP (MNP@SiO $\mathrm{MNH}_{2}$ ) and $\mathrm{N}$-succinyl feroxamine (3) using BOP

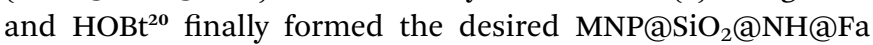
conjugate (4) through the formation of a covalent amide bond.

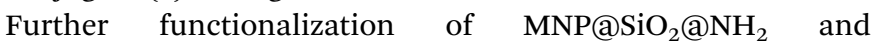
MNP@SiO ${ }_{2} @ N H @ F a(4) v i a$ nucleophilic reaction of $-\mathrm{NH}_{2}$ with $\mathrm{Boc}_{2} \mathrm{O}$ and succinic anhydride allowed us the introduction of Boc and carboxylic acid groups, respectively, in their free amine

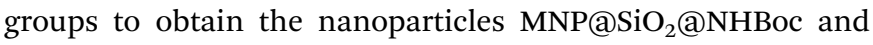
$\mathrm{MNP} @ \mathrm{SiO}_{2} @ \mathrm{NHCOOH}$ and the conjugates $\mathrm{MNP}_{2} \mathrm{SiO}_{2} @$

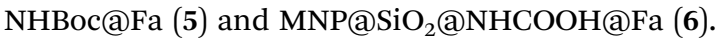

The final MNP@SiO $\mathrm{MNH}_{2} @ \mathrm{Fa}$ conjugate (4) and the MNP intermediate solids were characterized by different methods including powder XRD, Raman Spectroscopy, FTIR, XPS, magnetization studies, $\mathrm{Z}$ potential measurements, TEM and EDX mapping.

XRD analysis confirmed the crystalline structure of our synthetic magnetite (MNP) by comparing with the diffraction peaks of a standard magnetite JCPDS file 00-003-0863 (Fig. S1 $\dagger$ ).

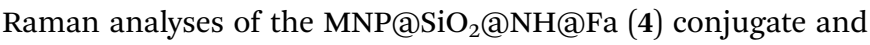
intermediates allowed us to confirm the silica coating and functionalization of the bare MNP (Fig. 2). The peaks present in all Raman spectra at $305.8,537.2$ and $665.6 \mathrm{~cm}^{-1}$ correspond to Fe-O vibrations. ${ }^{23}$ The appearance of a shoulder on the peak at $713.5 \mathrm{~cm}^{-1}$ in all spectra of silica coated MNP relates to $\mathrm{Si}-\mathrm{O}-\mathrm{Si}$

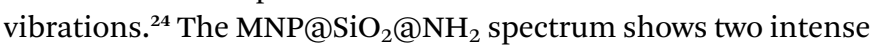
peaks at 1001.5 and $1027.4 \mathrm{~cm}^{-1}$ also associated to the presence of $\mathrm{SiO}_{2}$. The presence of two intense and well-defined peaks at

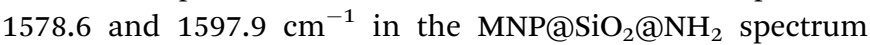
confirmed the formation of $\mathrm{Si}-\mathrm{C}$ bonds. Moreover, a shoulder observed at $703.0 \mathrm{~cm}^{-1}$ confirmed the presence of APTES

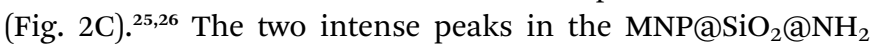
spectrum at $\sim 1570$ and $1590 \mathrm{~cm}^{-1}$ related to $\mathrm{Si}-\mathrm{C}$ bonds become a single broader peak centred at $\sim 1580 \mathrm{~cm}^{-1}$ in the

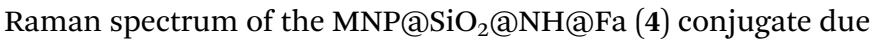
to the now presence of amide groups $\left(\sim 1630-1680 \mathrm{~cm}^{-1}\right) .{ }^{26}$

Fig. 3 shows the FTIR spectra of MNP, MNP@SiO

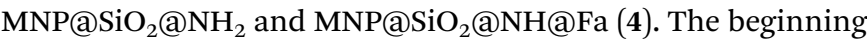
of a band within the spectral range of the analysis at $600 \mathrm{~cm}^{-1}$ in all the FTIR spectra relates to the Fe-O vibrations. The FTIR spectrum of MNP@SiO ${ }_{2}$ showed an intense and broad band at $1050 \mathrm{~cm}^{-1}$ corresponding to the $\mathrm{Si}-\mathrm{O}-\mathrm{Si}$ stretching vibration confirming the silica coating, and it is was also present in the 


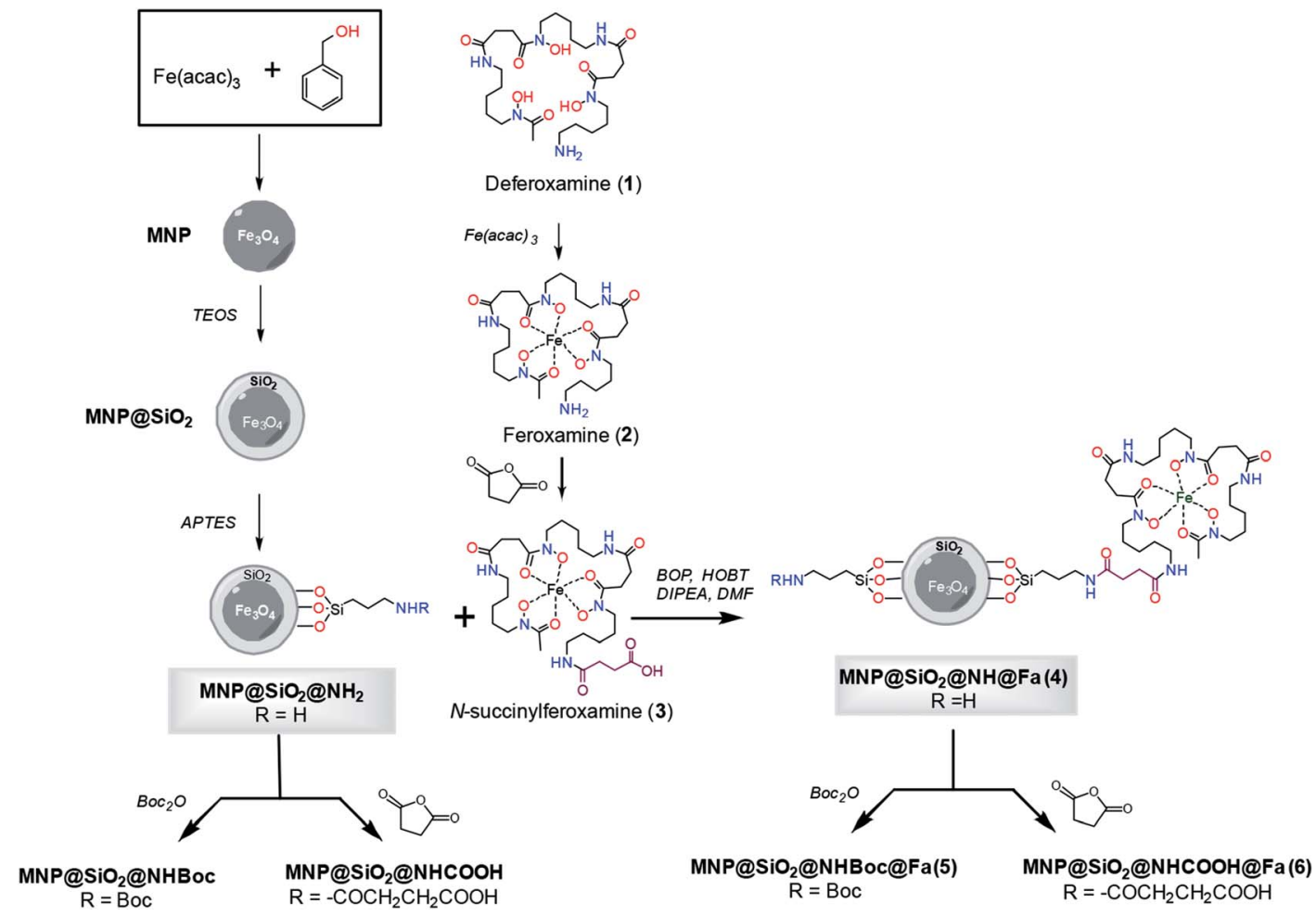

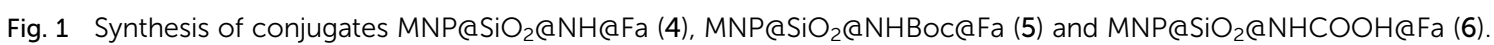

MNP@SiO ${ }_{2} @ \mathrm{NH}_{2}$ and $\mathrm{MNP} @ \mathrm{SiO}_{2} @ \mathrm{NH} @ \mathrm{Fa}$ (4) spectra. The broad band between 830 and $1275 \mathrm{~cm}^{-1}$ in the FTIR spectrum

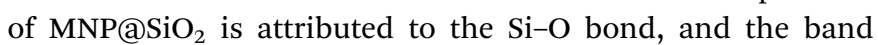

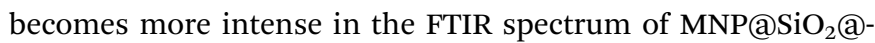
$\mathrm{NH}_{2}$ as a result of the functionalization of $\mathrm{MNP} @ \mathrm{SiO}_{2}$ with APTES and it is probably due to the $\mathrm{Si}-\mathrm{C}$ bond expected between 1175 and $1250 \mathrm{~cm}^{-1}$. Finally, the FTIR spectrum of MNP@SiO $@ N H @ F a(4)$ shows bands at $2995 \mathrm{~cm}^{-1}$ (C-H stretching bonds), $1640 \mathrm{~cm}^{-1}(\mathrm{O}=\mathrm{C}$ amide vibration $)$ and
$1577 \mathrm{~cm}^{-1}(\mathrm{O}=\mathrm{C}-\mathrm{N}$ hydroxamic acid vibration) that confirmed the presence of feroxamine conjugated with the nanoparticles. ${ }^{27}$

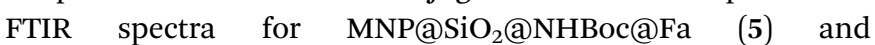
MNP@SiO ${ }_{2} @ N H C O O H @ F a(6)$ are shown in Fig. S2.†

Magnetization studies after coating and functionalization treatments were performed using hysteresis loop tests. The particles exhibit a superparamagnetic behavior, with only a little remanence and coercivity, which suggests the presence of a long-range magnetic dipole-dipole interaction among the
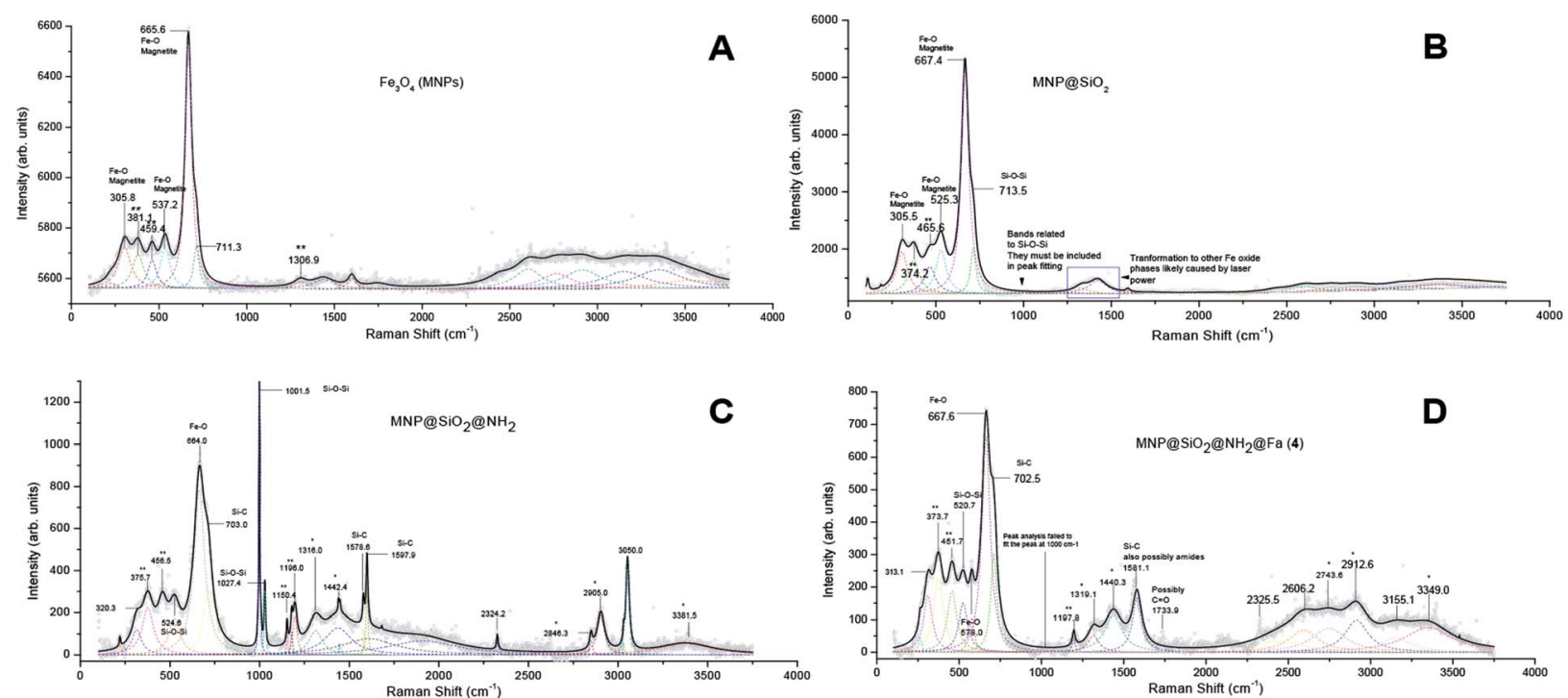

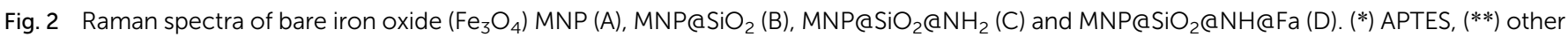
iron oxide phases, likely formed from the transformation of magnetite by the laser power. 


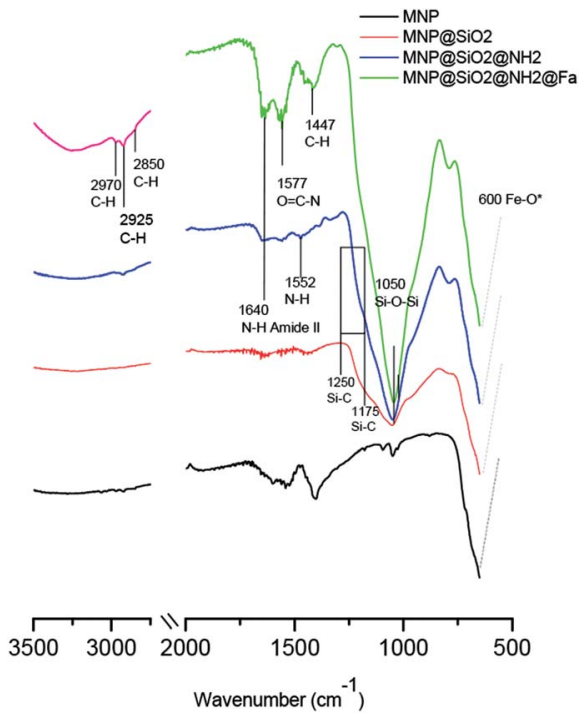

Fig. 3 FT-IR spectra of bare iron oxide $\left(\mathrm{Fe}_{3} \mathrm{O}_{4}\right)$ MNP (black),

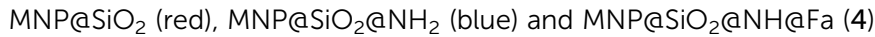
(green).

assemblies of superparamagnetic particles. The progressive decrease in magnetization saturation, $68.6 \mathrm{emu} \mathrm{g}^{-1}$ for MNP, $26.5 \mathrm{emu} \mathrm{g}^{-1}$ for $\mathrm{MNP} \mathrm{SiO}_{2}, 30.5 \mathrm{emu} \mathrm{g}^{-1}$ and $2.53 \mathrm{emu} \mathrm{g}^{-1}$

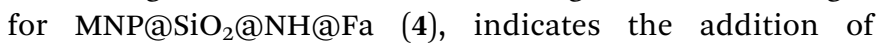
diamagnetic material on the MNP surface (Fig. S3†) and probably, the electron exchange between the surface Fe atoms and the ligands. Despite of magnetization decrease, the MNP@SiO ${ }_{2} @ N H @ F a(4)$ retained their superparamagnetic behavior after the treatments, suggesting that their magnetic properties are still active to allow magnetic separation after interaction with bacteria.

Fig. 4 shows the XPS spectra of the bare and different functionalized MNPs. The appearance of a peak at $\sim 285 \mathrm{eV}$ could be related in part to the carbon introduced during the functionalization process observed as $\mathrm{C}-\mathrm{C}$ and $\mathrm{C}-\mathrm{H}$, but also it could due to the presence of adventitious carbon on the samples. Nevertheless, the increasing intensity of the peaks observed at $286 \mathrm{eV}$ as the functionalization progresses is a good indicator of the presence of $\mathrm{C}-\mathrm{OH}, \mathrm{C}-\mathrm{O}-\mathrm{C}$ and $\mathrm{C}-\mathrm{N}$ in $\mathrm{MNP} @ \mathrm{SiO}_{2} @ \mathrm{NH}_{2}$,

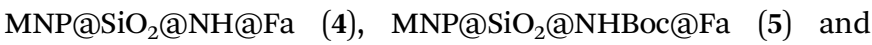

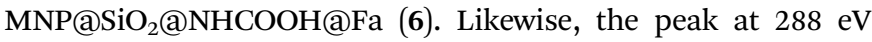
relates to the presence of $\mathrm{C}=\mathrm{O} / \mathrm{O}=\mathrm{C}$-bonds by the introduction of $t$-butoxycarbonyl (Boc) and carboxylic acid $(-\mathrm{COOH})$. The peak at $399 \mathrm{eV}$ in the N1s spectra confirms the formation of amide bonds between $\mathrm{MNP} @ \mathrm{SiO}_{2} @ \mathrm{NH}_{2}$ and feroxamine as observed in

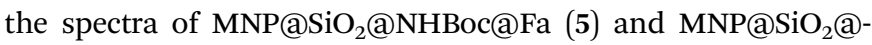
NHCOOH@Fa (6). Furthermore, the peak at $402 \mathrm{eV}$ is attributed to the $\mathrm{N}-\mathrm{O}$ bond of hydroxamic moieties. In all functionalized MNP, a peak at $102 \mathrm{eV}$ in Si2p spectra is observed, which is in good agreement with the the binding energy for the siloxane group..$^{28,29}$

The zeta potential for MNP and $\mathrm{MNP} @ \mathrm{SiO}_{2}$ were -25.21 and $-29.35 \mathrm{mV}$, respectively. The functionalization of $\mathrm{MNP} @ \mathrm{SiO}_{2}$

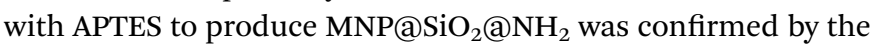
change of surface charge from negative to positive due to the presence of amine groups. ${ }^{30}$ The zeta potential remains positive for the conjugate $\mathrm{MNP} @ \mathrm{SiO}_{2} @ \mathrm{NH} @ \mathrm{Fa}$ (4) and the blocked

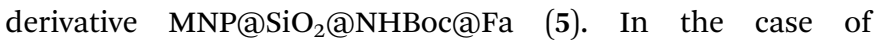

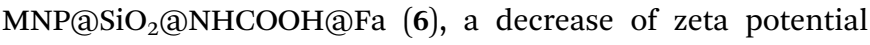
value $(10.96 \mathrm{mV})$ was observed in comparison with the value obtained for $\mathrm{MNP} @ \mathrm{SiO}_{2} @ \mathrm{NH} @ \mathrm{Fa}(4)(22.14 \mathrm{mV})$ which was attributed to the presence of carboxylic acid groups (Table 1).

The thermal loss of MNP (red line in Fig. 5) from 50 to $900{ }^{\circ} \mathrm{C}$ was $1.5 \%$, which might be due to residual loss of water and alcohol (the temperature range from 30 to $150{ }^{\circ} \mathrm{C}$, Fig. 5). The

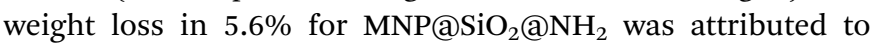
APTES degradation and also to the loss of small amount of water absorbed. The largest weight loss $(11.1 \%)$ was found to be for the conjugate $\mathrm{MNP} @ \mathrm{SiO}_{2} @ \mathrm{NH} @ \mathrm{Fa}(4)$, clearly indicating the presence of organic material on the surface. Furthermore,

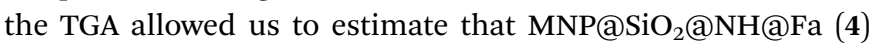
were obtained with approximately $7.62 \times 10^{-5} \mathrm{mmol}$ of feroxamine per $1 \mathrm{mg} \mathrm{MNP} @ \mathrm{SiO}_{2} @ \mathrm{NH}_{2}$. The TGA data for MNP@SiO $@$ @NHBoc@Fa (5) and MNP@SiO $\mathrm{M}_{2} @ \mathrm{NHCOOH@Fa}$ (6) conjugates can be seen in Fig. S4. $\dagger$

Fig. 6 shows bright field TEM images at medium and high

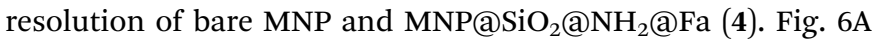
revealed that MNP were $\sim 10 \mathrm{~nm}$ in diameter, although bigger particles $(\sim 20 \mathrm{~nm})$ were also present. High resolution images confirmed the crystallinity of these nanoparticles as previously seen in the XRD analyses (Fig. 6B). The fringes observed in the TEM image correspond to d-spacings of 2.9 and $2.4 \AA$ of the crystal planes (220) and (311) of magnetite. ${ }^{31}$

The electron diffraction pattern showed bright spots that match with the (111), (220), (311), (400), (422), (511) and (440) diffraction planes of magnetite corresponding to d-spacings of 4.9, 2.9, 2.4, 2.0, 1.7, 1.6 and $1.4 \AA$, respectively (Fig. 6C). In addition, the presence of rings along with small spots demonstrated the formation of a polynanocrystalline magnetite. TEM images of $\mathrm{MNP} \mathrm{SiO}_{2} @ \mathrm{NH}_{2} @ \mathrm{Fa}(4)$ showed dispersed MNP particles $(\sim 10 \mathrm{~nm})$ embedded in the amorphous inorganicorganic material (Fig. 6D and E). The crystalline fringes of magnetite are still visible in high resolution and in the electron diffraction images (Fig. 6F).

Chemical composition of the nanoparticles after the $\mathrm{Si}$ coating was determined by energy dispersive X-ray (EDX) maps. Fig. 7A shows the high angle annular dark field (HAADF) image of $\mathrm{MNP}_{\mathrm{SiO}_{2}}$ and the maps for $\mathrm{Fe}, \mathrm{Si}, \mathrm{O}$ and $\mathrm{C}$. They show that

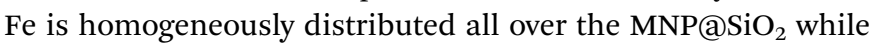
Si appears widely distributed not only throughout the nanoparticle, but also extended to the sides (i.e., coating layer is observed in the darker area of the HAADF image). On the other hand, C was detected in low concentrations likely due to contamination. Although similar results were observed for Fe, $\mathrm{Si}$ and $\mathrm{O}$ in the MNP@SiO $\mathrm{O}_{2} @ \mathrm{NH} @ \mathrm{Fa}$ (4) results, the concentration of $\mathrm{C}$ increased homogenously due to the addition of carbon layers on the nanoparticle surface (Fig. 7B).

\section{Bacteria capture studies}

Once the MNPs were characterized, we carried out experiments to evaluate the capabilities of bare and functionalized magnetic 


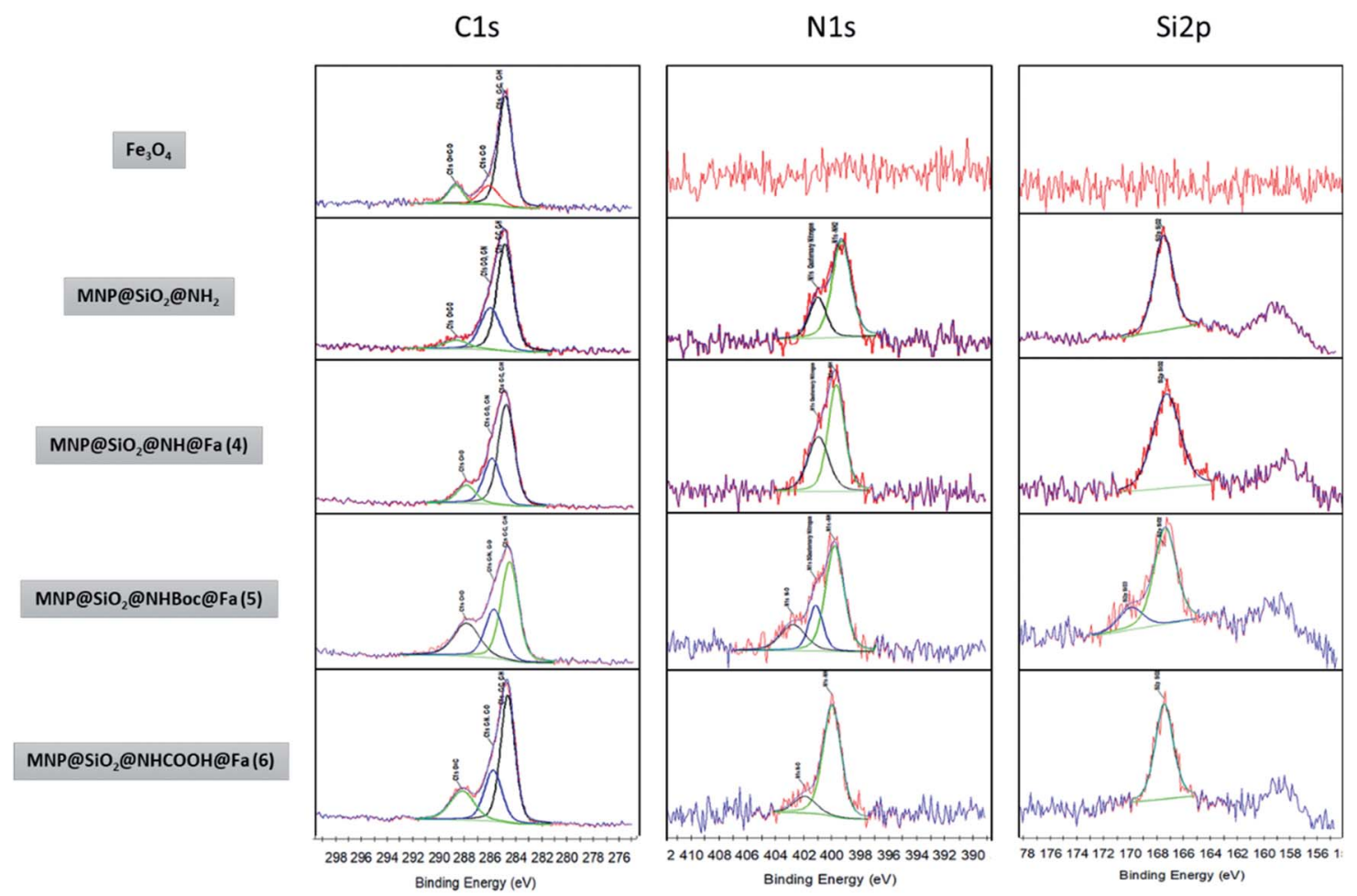

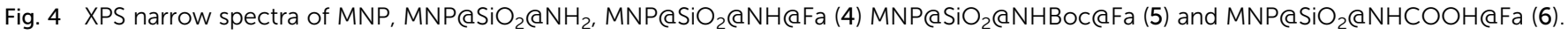

Table 1 Zeta potential measurements

\begin{tabular}{|c|c|}
\hline Sample & $Z$ potential \\
\hline MNP & -25.21 \\
\hline${\mathrm{MNP} @ \mathrm{SiO}_{2}}_{2}$ & -29.35 \\
\hline 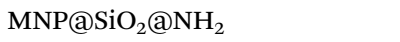 & 17.03 \\
\hline MNP@SiO ${ }_{2} @ N H @ F a(4)$ & 22.14 \\
\hline 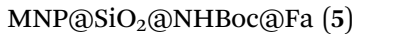 & 19.16 \\
\hline 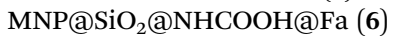 & 10.96 \\
\hline
\end{tabular}

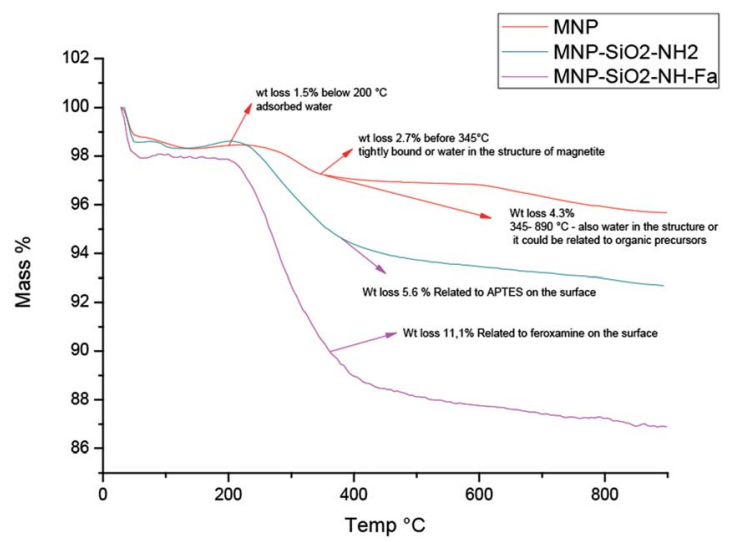

Fig. 5 Thermogravimetric analysis of MNP (red), MNPaSiO ${ }_{2} \mathrm{aNH}_{2}$ (green), and $\mathrm{MNP} \mathrm{aSiO}_{2} \mathrm{aNH}(\mathrm{Fa}$ (pink).
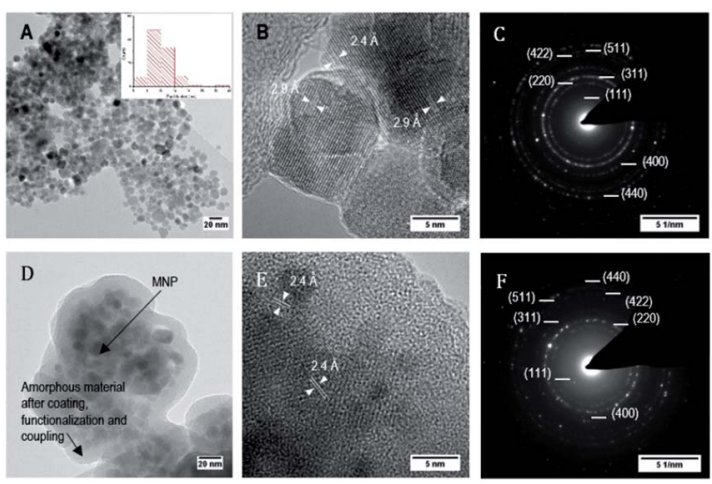

Fig. 6 Bright field TEM images and electron diffraction of bare MNP (A, $B$ and $C$ ), and of $M N P\left(S_{2} O_{2}(\mathrm{NH}(4 \mathrm{Fa}\right.$ (4) (D, E and F). Images at medium and high resolution.

nanoparticles to capture wild type (WC-A) and a mutant lacking feroxamine receptor FoxA (FoxA WC-A 12-8) Y. enterocolitica strains.

Bare MNP and functionalized MNPs were incubated in a PBS solution containing each $Y$. enterocolitica strain. The aggregates were then separated from the bacteria suspension by using a magnet. After rinsing the separated aggregates two times with PBS, they were re-suspended in PBS, to prepare serial dilutions that were plated for colony counting.

The results obtained from colony counting are shown in Fig. 8. Both $Y$. enterocolitica strains evaluated did not show a significant binding specificity for the functionalized MNP in relation to bare MNP. The lack of binding specificity is likely 
A
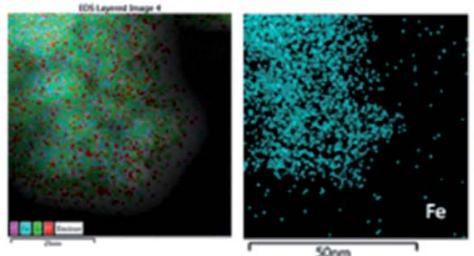

$\mathrm{Fe}$
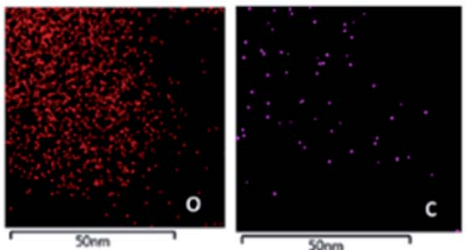

B
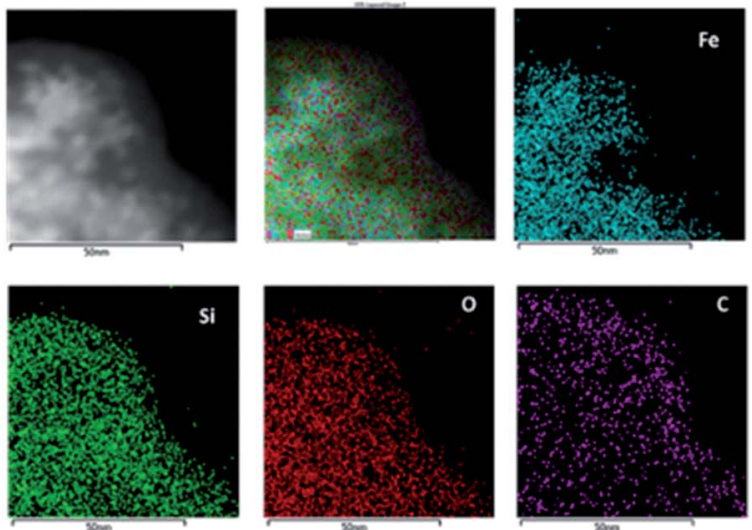

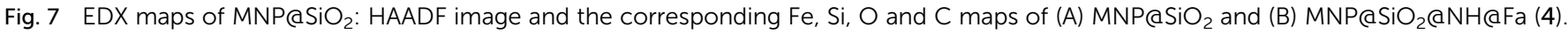

caused by surface interactions between nanoparticles and bacteria. Most bacteria have a net negative surface charge, particularly during the early stationary phase of cell growth, ${ }^{32,33}$ that makes them to preferentially interact with positively charged surfaces such as $\mathrm{MNP} @ \mathrm{SiO}_{2} @ \mathrm{NH}_{2}$, due to the presence of free amine groups through the protonation in physiologic solution. Therefore, our results are in good agreement with previous works reporting bacteria adsorption through free amine groups of functionalized $\mathrm{MNP}^{\mathbf{3 0 , 3 4 , 3 5}}$ The bacteria adsorption achieved with $\mathrm{MNP} \mathrm{SiO}_{2}$ particles can be attributed to mutually hydrophobic interaction. ${ }^{36}$

In order to reduce the non-specific binding behavior due to the electrostatic interactions between the free amine functionalized nanoparticles and bacteria, we made attempts to block the surface of the particles with two different groups, one of them of neutral nature (Boc) and a second group with polar character $(\mathrm{COOH})$. Boc groups were introduced onto ${\mathrm{MNP} @ \mathrm{SiO}_{2} @ \mathrm{NH}_{2} \text { and } \mathrm{MNP}_{2} \text { SiO }}_{2} @ \mathrm{NH} @ \mathrm{Fa}$ (4) by using (Boc) $)_{2} \mathrm{O}$ to give $\mathrm{MNP} @ \mathrm{SiO}_{2} @ N H B o c$ and conjugate

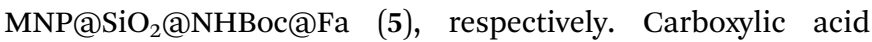
groups were also introduced onto the same conjugate by using succinic anhydride to give the corresponding $\mathrm{MNP} @ \mathrm{SiO}_{2} @$ $\mathrm{NHCOOH}$ and $\mathrm{MNP} @ \mathrm{SiO}_{2} @ \mathrm{NHCOOH} @ \mathrm{Fa}(6)$ similar to those reported by Gunawan and coworkers. ${ }^{34}$

When testing the bacteria capture with these new conjugates, the colony counting did not show any significant changes
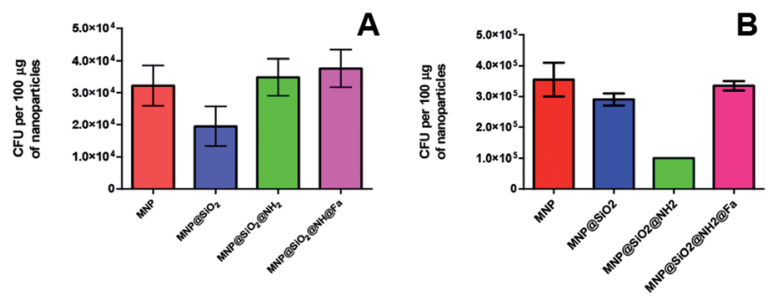

Fig. 8 CFU of $Y$. enterocolitica captured per $100 \mu \mathrm{g}$ of magnetic nanoparticles: bare, MNPaSiO $2, M N P\left(\mathrm{SiO}_{2} \mathrm{aNH}_{2}\right.$ and $\mathrm{MNP}_{2} \mathrm{CSiO}_{2} \mathrm{a}-$ $\mathrm{NH}$ aFa (4). (A) WC-A (wild type) (B) FoxA WC-A 12-8 (mutant lacking feroxamine receptor FoxA).
A

B

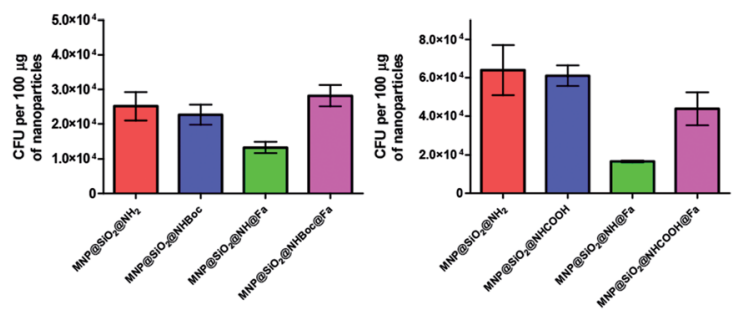

Fig. 9 CFU of $Y$. enterocolitica WC-A (wild type) captured per $100 \mu \mathrm{g}$ of magnetic nanoparticles (A) MNP@SiO $2 \mathrm{aNH}_{2}, \mathrm{MNP} @ \mathrm{SiO}_{2} @ \mathrm{NHBoc}$

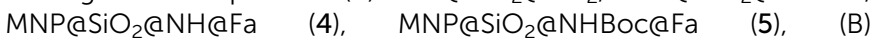
$\mathrm{MNP} \propto \mathrm{SiO}_{2} \mathrm{aNH}_{2}, \mathrm{MNP} \propto \mathrm{SiO}_{2} @ \mathrm{NHCOOH}, \mathrm{MNP} \mathrm{SSiO}_{2} @ \mathrm{NH} @ \mathrm{Fa}$ (4), $\mathrm{MNPaSiO}{ }_{2} @ \mathrm{NHCOOH}(\mathrm{Fa}$ (6).

for the adsorption of $Y$. enterocolitica WC-A (wild type strain) indicating that the molecular recognition of the siderophore again was not observed (Fig. 9A and B). Thus, these modifications were not enough to attenuate the electrostatic interactions between bacteria and the modified nanoparticles as confirmed with the low decrease value of zeta potential (Table 1). Similar results were obtained when the experiments were repeated with and without iron deficiency growth conditions (Fig. S8 $\dagger$ ).

Fig. 10A shows the attachment of the nano-sized conjugate MNP@SiO ${ }_{2} @ N H @ F a(4)$ to the surface of Y. enterocolitica WC-A.
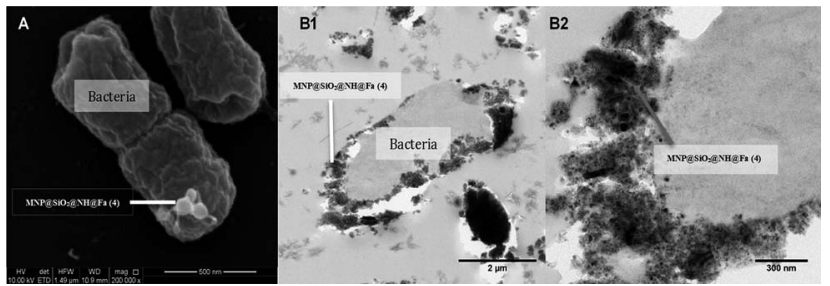

Fig. 10 (A) SEM images of $Y$. enterocolitica WC-A interacting with $M N P\left(\mathrm{SiO}_{2} \mathrm{aNH}(\mathrm{Fa}\right.$ (4). (B) TEM images of $Y$. enterocolitica WC-A interacting with $\mathrm{MNP}\left(\mathrm{SSiO}_{2} @ \mathrm{NH} @ \mathrm{Fa}\right.$ (4), (B1) attachment of nanoparticles to the surface of a single bacteria, (B2) detail of the attachment on the bacterial membrane. 
The corresponding thin-sectioned samples measured by TEM (Fig. 10B1 and B2) confirmed the capability of the modified nanoparticles to attach to the bacterial membrane. Additional images and EDX maps are shown in Fig. S7 of the ESI. $\dagger$

\section{Conclusions}

In this study, we describe the preparation of the conjugate MNP@SiO ${ }_{2} @ N H @ F a(4)$ using surface modified magnetic nanoparticles and deferoxamine iron(III) complex (feroxamine) and its structural characterization using several techniques.

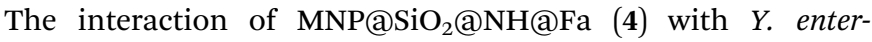
ocolitica WC-A and FoxA WC-A 12-8 showed no significant difference in the number of colonies captured in relation to

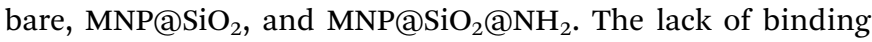
specificity was attributed to the presence of electrostatic forces such as the positive charged free amine groups present in $\mathrm{MNP} @ \mathrm{SiO}_{2} @ \mathrm{NH}_{2}$ and the low concentration of siderophore membrane receptor in bacteria. These results suggest that the electrostatic and other surface interactions are dominant over those due to the molecular recognition between MNP conjugate and feroxamine receptor. The effect of free amine groups and the change of charge on the surface were evaluated with Boc and $\mathrm{COOH}$ groups in $\mathrm{MNP} @ \mathrm{SiO}_{2} @ \mathrm{NHBoc@Fa} \mathrm{(5)} \mathrm{and}$ MNP@SiO ${ }_{2} @ \mathrm{NHCOOH@Fa} \mathrm{(6),} \mathrm{respectively.} \mathrm{Unfortunately,}$ these new conjugates did not improve bacteria capture. Further efforts are needed to explore other blocking materials in order to remove or decrease non-specific binding of magnetic nanoparticles surface to bacteria. While the reported siderophorebased methods for detection of microbial pathogens allow the detection of the target bacteria, the development of the present strategy would also allow bacteria isolation from a complex mixture of microorganisms for their posterior identification.

\section{Conflicts of interest}

There are no conflicts to declare.

\section{Acknowledgements}

The authors gratefully acknowledge Professor Klaus Hantke (University of Tübingen, Germany) for kindly supply the Yersinia enterocolitica strains used in this work. This work was supported by grants AGL2015-63740-C2-2-R and AGL2015-63740-C2-1-R (AEI/FEDER, EU) from the State Agency for Research (AEI) of Spain, both co-funded by the FEDER Programme from the European Union.

\section{Notes and references}

1 Y. Pan, X. Du, F. Zhao and B. Xu, Chem. Soc. Rev., 2012, 41, 2912-2942.

2 R. A. Bohara, N. D. Thorat and S. H. Pawar, RSC Adv., 2016, 6, 43989-44012.

3 O. Lazcka, F. J. Del Campo and F. X. Muñoz, Biosens. Bioelectron., 2007, 22, 1205-1217.
4 T. Mocan, C. T. Matea, T. Pop, O. Mosteanu, A. D. Buzoianu, C. Puia, C. Iancu and L. Mocan, J. Nanobiotechnol., 2017, 15, 25.

5 T. Zheng and E. M. Nolan, Metallomics, 2012, 4, 866-880.

6 R. C. Hider and X. Kong, Nat. Prod. Rep., 2010, 27, 637-657.

7 M. Sandy and A. Butler, Chem. Rev., 2010, 109, 4580-4595.

8 D. D. Doorneweerd, W. A. Henne, R. G. Reifenberger and P. S. Low, Langmuir, 2010, 26, 15424-15429.

9 Y. Kim, D. P. Lyvers, A. Wei, R. G. Reifenberger and P. S. Low, Lab Chip, 2012, 12, 971-976.

10 T. Inomata, H. Eguchi, Y. Funahashi, T. Ozawa and H. Masuda, Langmuir, 2012, 28, 1611-1617.

11 T. Inomata, H. Tanabashi, Y. Funahashi, T. Ozawa and H. Masuda, Dalton Trans., 2013, 42, 16043-16048.

12 J. Hu, M. Ghosh, M. J. Miller and P. W. Bohn, Anal. Methods, 2019, 11, 296-302.

13 S. Wu, Z. Zhang, X. Wang, M. Zhang, J. Peng, Z. Xie and D. Pang, J. Phys. Chem. C, 2009, 113, 9169-9174.

14 N. Bugdahn, F. Peuckert, A. G. Albrecht, M. Miethke, M. A. Marahiel and M. Oberthür, Angew. Chem., Int. Ed., 2010, 49, 10210-10213.

15 N. Pinna, S. Grancharov, P. Beato, P. Bonville, M. Antonietti and M. Niederberger, Chem. Mater., 2005, 17, 3044-3049.

16 Y. S. Li, J. S. Church, A. L. Woodhead and F. Moussa, Spectrochim. Acta, Part A, 2010, 76, 484-489.

17 J. P. Chen, P. C. Yang, Y. H. Ma, S. J. Tu and Y. J. Lu, Int. J. Nanomed., 2012, 7, 5137-5149.

18 D. Goswami, M. T. Machini, D. M. Silvestre, C. S. Nomura and B. P. Esposito, Bioconjugate Chem., 2014, 25, 2067-2080.

19 J. D. Herscheid, a Hoekstra and C. M. Vos, Eur. J. Nucl. Med., 1984, 9, 508-510.

20 K. El-Boubbou, C. Gruden and X. Huang, J. Am. Chem. Soc., 2007, 129, 13392-13393.

21 M. D. Abràmoff, P. J. Magalhães and S. J. Ram, Biophotonics Int., 2004, 11, 36-42.

22 J. Yañez-Vilar, M. Sánchez-Andujar, S. Castro-García, J. Mira, J. Rivas and M. A. Señarís-Rodríguez, Bol. Soc. Esp. Ceram. Vidrio, 2010, 49, 81-88.

23 O. N. Shebanova and P. Lazor, J. Solid State Chem., 2003, 174, 424-430.

24 P. González, J. Serra, S. Liste, S. Chiussi, B. León and M. Pérez-Amor, J. Non. Cryst. Solids, 2003, 320, 92-99.

25 M. Veres, M. Koós, S. Tóth, M. Füle, I. Pócsik, A. Tóth, M. Mohai and I. Bertóti, Diam. Relat. Mater., 2005, 14, 1051-1056.

26 Y. You, T. Yu, J. Kasim, H. Song, X. Fan, Z. Ni, L. Cao, H. Jiang, D. Shen, J. Kuo and Z. Shen, Appl. Phys. Lett., 2008, 93, 103111-103113.

27 O. Cozar, N. Leopold, C. Jelic, V. Chis, L. David, A. Mocanu and M. Tomoaia-Cotisel, J. Mol. Struct., 2006, 788, 1-6.

28 N. Graf, E. Yegen, T. Gross, A. Lippitz, W. Weigel, S. Krakert, A. Terfort and W. E. S. Unger, Surf. Sci., 2009, 603, 28492860.

29 W. Michaeli, C. J. Blomfield, R. D. Short, F. R. Jones and M. R. Alexander, Appl. Surf. Sci., 2002, 137, 179-183.

30 W. Fang, C. Han, H. Zhang, W. Wei, R. Liu and Y. Shen, RSC Adv., 2016, 6, 67875-67882. 
31 X. Teng and H. Yang, J. Mater. Chem., 2004, 14, 774-779.

32 H. Hayashi, H. Seiki, S. Tsuneda, A. Hirata and H. Sasaki, J. Colloid Interface Sci., 2003, 264, 565-568.

33 N. P. Boks, H. J. Busscher, H. C. Van Der Mei and W. Norde, Langmuir, 2008, 24, 12990-12994.
34 A. E. Liana, C. P. Marquis, C. Gunawan, J. J. Gooding and R. Amal, Colloids Surf., B, 2017, 151, 47-57.

35 S. Zhan, Y. Yang, Z. Shen, J. Shan, Y. Li, S. Yang and D. Zhu, J. Hazard. Mater., 2014, 274, 115-123.

36 H. H. Tuson and D. B. Weibel, Soft Matter, 2013, 9, 43684380. 